\title{
A DEBATE: ENTRE «FEMINISMO» ANARQUISTA Y EL FEMINISMO BURGUÉS
}

\author{
DISCUSSION: BETWEEN THE ANARCHIST «FEMINISM» \\ AND BOURGEOIS FEMINISM
}

\author{
Coral CuAdradA MAJÓ \\ Universidad Rovira y Virgili \\ Ginés PUENTE PÉREZ \\ Institut Interuniversitari d'Estudis de Dones i Gènere
}

Recibido: 31/7/2016

Aceptado: 26/10/2016

Para citar este artículo / To cite this article:

Cuadrada Majó, Coral y Puente Pérez, Ginés. «A debate: Entre "Feminismo" anarquista y el Feminismo burgués». En Nieves Montesinos Sánchez y Beatriz Souto Galván (coords.), Laicidad y creencias. Feminismo/s, 28 (diciembre 2016): 25-47, DOI: 10.14198/fem.2016.28.01

Para enlazar con este artículo / To link to this article:

http://dx.doi.org/10.14198/fem.2016.28.01

\section{Resumen}

El objetivo del presente trabajo es el de comparar diversas propuestas de mujeres que lucharon por conseguir una sociedad más justa. Analizaremos como las anarquistas y las feministas burguesas, desde ideologías y posiciones divergentes, cuanto no antagónicas, abordaron la educación, el laicismo, la maternidad y el matrimonio. Para desarrollar nuestro propósito hemos considerado oportuno, mediante las sugerencias del feminismo dialógico, utilizar sus textos y ponerlos a debate, tal como si de una discusión se tratara.

Palabras clave: anarquismo, educación, feminismo burgués, feminismo dialógico, laicismo, maternidad, matrimonio y religión. 


\begin{abstract}
The aim of this study is to compare various proposals of women who fought for a more just society. We analyze how these anarchists and bourgeois feminists, from divergent ideologies andpositions, addressed issues as education, secularism, motherhood and marriage. With this purpose we have considered appropriate touse their texts and make them debate as if it was adiscussion, following the suggestions of dialogic feminism.
\end{abstract}

Keywords: anarchism, education, bourgeois feminism, dialogic feminism, laicism,maternity, marriage and religion. 


\section{PRESENTACIÓN}

La construcción de la laicidad y, con ella, la superación de creencias conservadoras y ancladas en los dictámenes de la Iglesia católica, pareciera un aspecto resuelto si creyéramos que se cumplen a pies juntillas los enunciados de la Constitución española. Nada más lejos de la realidad. En las mentes de todas afloran, sin demasiado esfuerzo, las manifestaciones pro-vida, los planes fallidos de Gallardón con su discutida reforma de la ley del aborto (Cuadrada 2015, 112-126), la protección a las escuelas religiosas y el mantenimiento -cuasi incuestionable- del Concordato con la Santa Sede, solicitado por Franco a Pío XII en 1951, materializado dos años después. A pesar de encontrarnos en la tesitura actual, tan inmovilista en tantos sentidos, la historia de las mujeres nos muestra los intentos y las voluntades de pioneras que, desde el siglo XIX, defendieron con ahínco y valor sus ideas en pro de una sociedad más igualitaria y más laica. Desde una perspectiva simplista, carente de conocimiento histórico, podríamos atribuir los avances a las defensoras de los derechos de las mujeres, que hoy en día llamaríamos feministas; sin embargo, algunas de ellas no quisieron en los primeros momentos ser denominadas así, puesto que ese feminismo se asociaba a la burguesía.

La palabra «feminismo» es en sí misma problemática en su utilización, dado el rechazo que dicho término encontró en la mayoría de las mujeres militantes en las filas del anarquismo. Connotando, para ellas, la versión burguesa de las emancipadas de buenas familias (Espigado 13).

Nuestra aportación, fruto de reflexiones conjuntas en torno al tema, nos lleva a discurrir sobre las acciones emprendidas por las anarquistas, contraponiéndolas con las promovidas por el feminismo burgués. Un planteamiento dialéctico, un debate escrito a cuatro manos, que analiza las concepciones de la familia, la formación de las niñas y los roles de género, desde una y otra perspectiva. Encontraremos posturas vanguardistas a la par de resistencias notables, antagonismos y controversias que nos ayudarán a valorar iniciativas y a entender los porqués de las anarquistas en refutar el apelativo de feministas. Pero no sólo eso. Nuestra intención es más amplia: pretendemos ahondar y reconocer el proceso hacia el laicismo, repensando los porqués de las ácratas y también de 
las burguesas, porqués que las condujeron a planteamientos concretos respecto a la religión, el matrimonio, la maternidad y, muy en especial, la educación.

\section{METODOLOGÍA}

A nivel teórico-metodológico este trabajo se basa en la Metodología de Investigación Feminista (MIF). La premisa del conocimiento feminista se fundamenta -a diferencia del patriarcal- en la validez de la experiencia de las mujeres, además de la de los hombres (Biglia 195-229). Desde una perspectiva feminista se intenta revalorizar la figura de unas autoras que propusieron una serie de demandas teóricas en nombre de la conciencia colectiva.

Partimos de la firme creencia de que el peso que juega el contexto en las investigaciones históricas es fundamental, en cuanto a que los datos científicos que se recogen y construyen están inevitablemente marcados por un espacio y un tiempo específicos. En este sentido, la MIF implica un trabajo importante de análisis del contexto, que hace hincapié en aquellos tópicos sociales y culturales que se mantienen y que no se sustentan sobre planteamientos lógicos, pero que todavía imperan como creencias firmes. Un conocimiento, el feminista, que se construye socialmente y rehúsa la imagen de una historiadora o historiador que controle el sujeto y el proceso de investigación (England 80-89).

Los feminismos siempre han buscado nuevas formas de análisis para repensar los problemas sociales. En nuestro caso partimos también de las propuestas del feminismo dialógico que nos interesa, especialmente, por lo que aporta en relación con el discurso y el entendimiento entre diferencias teóricas. Las historiadoras feministas nos encargamos de interpretar, observar y analizar los documentos con la finalidad de estructurar un discurso crítico, capaz de acercarnos a las sociedades pasadas; no obstante, muchas veces se nos olvida que los textos hablan por sí solos. Cada párrafo nos sugiere y nos oculta por igual: debemos ser capaces de darnos cuenta de ello. El método dialógico parte de esta observación y, así, pretendemos hacer que los textos dialoguen entre ellos. De esta manera mostraremos la existencia de diferentes realidades y puntos de vista opuestos en un mismo contexto. Se creará una conversación a partir de la documentación en la que se permita a cada quién extraer conclusiones y, del mismo modo, se posicione ante lo que unas y otras defienden.

\section{LAS MUJERES ESPAÑOLAS, SEGÚN DOÑA EMILIA PARDO BAZÁN}

A partir de la segunda mitad del novecientos pueden definirse hasta tres corrientes feministas en el Estado español. Por un lado, aquella que entendía a la mujer como un ser relacional (madre y esposa) y que, desde esa premisa, pedía 
reformas en la sociedad y en la educación; por otro, aunque más minoritaria, la liderada por Emilia Pardo Bazán, defendiendo la necesidad de igualdad social y legal para las mujeres como personas independientes y autónomas; y, por último, las posturas de mujeres como Teresa Mañé, Teresa Claramunt y Antonia Maymón, entre otras, quienes irían un paso más allá en sus reivindicaciones y en sus teorías (Prado 110). Todas sus intervenciones iban encaminadas, como apunta Díaz Marcos (2012), a incidir y modificar la realidad que les tocó vivir.

Pardo Bazán (1851-1921), aristócrata, escritora, periodista, traductora, editora, catedrática y conferenciante, en La España Moderna tradujo cuatro artículos en torno a «La mujer española» (Pardo Bazán 1976), publicados originariamente en la Fortnightly Review, una de las revistas más importantes e influyentes en la Inglaterra de entonces. Sus descripciones no sirven únicamente para tomar el pulso a la intensidad feminista de la autora (Bieder 1998, 25-54), sino en especial -y por lo que ahora nos interesa- para exponer, en palabra y opinión de una coetánea, las condiciones sociales de las mujeres de su época:

Nótese cómo siempre que la mujer española revela interés político, se adhiere a la España antigua; la nueva, socialmente hablando, no se ha formado su elemento femenino (31-32).

Una idea central recorre los ensayos: la mujer es lo que el hombre ha querido que sea, y esta dependencia atenúa, en buena medida, su responsabilidad:

Los defectos de la mujer española, dado su estado social, en gran parte deben achacarse al hombre, que es, por decirlo así, quien modela y esculpe el alma femenina (75).

Parte de una base de interpretación clasista, mediatizada por las posibilidades económicas y por los deberes y oportunidades sociales. Contraría la confusión de clases, pasando revista de ellas, alineándose con la nobleza, a la cual pertenece. Reserva así sus halagos para el intelectualismo de algunas aristócratas, aunque censure su ociosidad y superficialidad. Fijándose en el otro extremo, no disimula sus simpatías por las mujeres del pueblo, a su entender las protagonistas de la única clase que ha sabido conservar el carácter nacional -aprecia singularmente a la campesina gallega y a la obrera e industrial catalana-, de las que resalta su originalidad, espontaneidad y dedicación al trabajo:

La hija del pueblo, chiquita aún, aprende ya a agenciarse el pedazo de pan haciendo recados, sirviendo, cosiendo, en la fábrica de tejidos, en la de cigarros, pregonando sardinas o legumbres, llevando las vacas al pasto o labrando la tierra (40). 
Su crítica más severa se dirige en contra de las burguesas, de las que ofrece un panorama pésimo, y a las que tilda de cursis y vulgares; sobre todo, por sus afanes en imitar a las nobles. De las mujeres de clase media denuncia su pereza, incultura, mediocridad, ridiculez, el continuo «quiero y no puedo», su estrechez de miras y falta de energía, elementos todos ellos causantes del estado de dependencia e inferioridad en el que habitan:

¿Ejercer una profesión, un oficio, una ocupación cualquiera? ¡Ah! Dejarían de ser señoritas ipso facto [...] Quédense en la casa paterna, criando moho, y erigidas en convento de monjas sin vocación: viendo deslizarse su triste juventud, precursora de una vejez cien veces más triste; reducidas a comer mal y poco, a sufrir mil privaciones, para lograr sus objetivos en que fundar su única esperanza de mejor porvenir. Primero, que tengan carrera los hermanos varones y puedan «hoy o mañana» servirlas de amparo; segundo, no carecer de cuatro trapitos con que presentarse en público de manera decorosa, a ver si aparece el ave fénix, el marido que ha de resolver la situación [...] La modesta familia mesocrática escatima los garbanzos del puchero a trueque de que las niñas se presenten en paseos, teatros y reuniones bien emperejiladas con todos los aparejos convenientes para la pesca conyugal (49).

Con Emilia Pardo Bazán, quien se encuentra en el entreacto de unas y otras propuestas, hemos querido iniciar esta reflexión comparativa. Ella misma, situada en este espacio, reflexiona sobre la necesidad de una metamorfosis social capaz de transformar el yugo opresor de las mujeres.

\section{RELIGIÓN, MATRIMONIO, MATERNIDAD}

A lo largo del siglo XIX, la práctica religiosa se relega al ámbito privado, coincidiendo con el lugar reservado a las mujeres. Este puede ser uno de los motivos del porqué a lo largo de la centuria se produjo una feminización de la religión, con un aumento significativo del número de mujeres que ingresaban en órdenes religiosas. La Inmaculada Concepción, imagen simbólica femenina, es una advocación y dogma de esa época, a la que se dota de un carácter global para reconquistar la posición de la Iglesia en la sociedad. Frente a otras formas de organización de las mujeres -juntas patrióticas, tertulias-, las peticiones colectivas se presentan como una forma de acción de ciudadanía favorable a la Iglesia. Ésta, que en origen condena los principios básicos del liberalismo y lo define como el paradigma del desorden, se reposiciona para entablar una nueva lucha conjunta por la hegemonía católica frente a un sujeto emergente: el movimiento obrero.

La Iglesia se suma, de esta manera, a la movilización de masas a nivel político y para ello aparecen sindicatos católicos con algunos servicios sanitarios, educativos, etc. La vinculación a asilos, orfanatos y toda una suerte de 
instituciones semejantes, conlleva un tejido de mujeres que participan «cuando fue menester» en la vida social -espacio público, no político-. Así se asocia la caridad con la proyección de la maternidad.

Las mujeres católicas, al igual que muchos ciudadanos varones, se suman a las protestas de la cúpula eclesiástica contra la reforma de la base $2 .^{a}$ de la Constitución que promueve la libertad de culto y la tolerancia de prácticas religiosas distintas de la católica (1854-1855). En lo que divergen las peticiones de hombres y mujeres no es en el objetivo compartido, sino en las justificaciones de su iniciativa. Las mujeres católicas argumentan su participación apelando a cuestiones emotivas-«haciendo justicia a nuestros sentimientos»- y a la maternidad - «pero tratándose de intereses religiosos, los corazones de las que aprecian la dignidad del dulce nombre de madres [...] no nos permiten guardar igual silencio». En principio, las mujeres españolas que presentan estas peticiones no buscan la adquisición de derechos políticos; sus constantes se centran en los roles de género tradicionales para ratificar su acción:

...decid a las naciones que España no admite más religión que la católica apostólica romana y así podréis regresar con frente erguida a vuestro hogar, para recibir los abrazos de vuestras madres, hermanas, hijas y esposas (Señoras de Barcelona, 24 febrero 1855).

Las que suscriben, esposas, madres, hijas de todas las clases de la sociedad sin distinción de condiciones ni jerarquías (Señoras de Madrid, Sin fecha).

Por contraposición, a partir de la segunda mitad de la centuria, muchas de las anarquistas observan la religión como una de las causas principales de la exclusión y opresión de las mujeres, tanto en el espacio público como en el privado. El anarquismo se opone, en la búsqueda para obtener la emancipación social, a cualquier tipo de organismo jerárquico que pueda suponer una limitación forzosa de la libertad y obstruya la intelectualidad. De ahí que los discursos laicistas, ateos, ácratas, librepensadores y, por consiguiente, anarquistas, ataquen y denuncien constantemente a la Iglesia, como representante, junto al Estado, de un sistema autoritario de dominación de clase y opresión social. En este sentido, el laicismo debe entenderse como el intento de construcción de una sociedad consciente, educada en un nuevo modelo. Un modelo capaz de garantizar a la humanidad la recuperación de la conciencia y la condición natural de la libertad (Álvarez).

Si en algo coinciden el socialismo y el anarquismo -aunque por diferentes motivos- es en la definición del catolicismo como la traba mental e ideológica para la elevación espiritual de la clase trabajadora y la transformación de sus condiciones materiales a través de la lucha de clases (Macoc 164). Para Teresa Mañé Miravent (1865-1939), maestra, editora y escritora (alias Soledad 
Gustavo), el ateísmo es la evolución más absoluta y positiva de la religión -como consecuencia directa del librepensamiento-; de igual manera la anarquía es resultado de la evolución más absoluta de la política (Marín y Palomar 34). Su oposición a Dios lleva a Mañé a oponerse a autores de renombre. Piensa que Voltaire estaba totalmente equivocado al decir que si Dios no existiese hubiese sido preciso inventarlo. Al contrario, según la autora, «si existiese el Dios que nos pintarrajea el catolicismo sería preciso destruirlo». Lejos de compartir las propuestas que enaltecen la figura de Dios, Mañé critica los fundamentos de la religión; plantea que Dios no ha hecho nada para mejorar las condiciones sociales de mujeres; rebate de esta manera la omnipotencia y benevolencia divinas:

¡Embaucadores! á existir este poder clemente y misericordioso no hubiera permitido que vuestra vituperina lengua, se hubiera inmiscuido en mis más puras acciones y hubiera hecho que fuera descubierta la verdad de vuestro difamador proceder (Gustavo 1888).

La apología del ideal femenino ejemplar y, a la vez, piadoso, caritativo y socialmente activo, supone la evolución del modelo de mujer instaurado desde la edición de La perfecta casada de Fray Luís de León, «el ángel del hogar», vigente desde el siglo XVI y aún vivo, casi inmutable, a finales del XIX. Las tímidas medidas comenzadas por la I República en pro de la igualdad entre hombres y mujeres se sustituyen por la discriminación anterior en el Código Penal de 1870 y el Civil de 1889. En ambos, el discurso de género se centra en ratificar la jerarquía masculina, la definición de los deberes matrimoniales en términos de protección/obediencia, o la administración económica por parte del esposo. Medidas enraizadas en el orden natural universal y los postulados de género del catolicismo -derecho canónico-, asumiendo sus fórmulas en el establecimiento del contrato matrimonial (Scanlon 122-129). Además, se ratifica oficialmente la doble moral, penalizando de forma diferencial las conductas consideradas deshonestas, erigiendo a las mujeres en las garantes de la moralidad y la esencia de la familia, mientras que en los hombres se fomenta una inmoralidad impune (Scanlon 130-137). Pardo Bazán denuncia la estupidez de las costumbres y minusvaloración de las mujeres:

Siendo el matrimonio y el provecho lo que reporta la única aspiración de la burguesa, sus padres tratan de educarla con arreglo a las ideas o preocupaciones del sexo masculino [...] Este sistema educativo, donde predominan las medias tintas, y donde se evita como un sacrilegio el ahondar y el consolidar, da un resultado inevitable: limita a la mujer, la estrecha y reduce, haciéndola más pequeña aún que el tamaño natural, y manteniéndola en perpetua infancia (85). 
De ahí los numerosos fracasos en el terreno conyugal. La falta de formación merma la independencia, libertad de elección y criterio de esas jóvenes, las cuales acaban aceptando al primer postor, el novio concertado por sus padres, o cediendo al matrimonio por interés. La crítica de la condesa es implacable contra esa sociedad que reprueba y censura con extrema dureza en la mujer las mismas acciones que halaga, ríe y celebra en el varón.

En contraposición, la idea de amor libre defendido por las ácratas es uno de los temas que generan más controversias y escándalo en esa sociedad moralizada y moralizante. Anarquistas y periodistas de La Voz de la Mujer como Carmen Lareva acusaban a las relaciones sentimentales como la causa principal de la subyugación de las mujeres:

Se nos ha dicho que si el amor la unión, etc., fueran libres, como deseamos, el hombre cambiaría continuamente de mujer y la mujer de compañero, que no teniendo nada que temer a la sociedad ni de la ley, no serían ya sea porque la ley castiga a la adúltera o adúltero, o bien por temor a la crítica social, los esposos se soportan mutuamente sus faltas y rarezas.

Nada, queridas compañeras, tan incierto como eso. Tanto en uno como en otro sexo lo que se busca, no es la satisfacción de un apetito más o menos carnal, no, lo que se busca es la felicidad, la dicha, la tranquilidad... (La Voz de la Mujer, Lavera).

A ello también prestó atención otra ensayista, Pepita Guerra, quien, igualmente, instaba a las mujeres,

¡Jóvenes, niñas, mujeres en general, de la presente sociedad!

Si no queréis convertiros en prostitutas, en esclavas sin voluntad de pensar ni sentir, ¡no os caséis! (Guerra)

En este contexto, Concepción Arenal (1820-1893), escritora y visitadora de cárceles, lanzó una propuesta novedosa, centrada en la necesidad de ejercicio de virtudes sociales, tanto para el bien de las propias mujeres como para el de toda la sociedad:

... la mujer de su casa es un ideal erróneo [...] señala el bien donde no está; corresponde a un concepto equivocado de la perfección, que es para todos el progreso y que se pretende que sea para ella la inmovilidad $(1974,202)$.

La mujer, según Arenal, era la que conserva en el hogar el fuego sagrado de los sentimientos religiosos. El hombre -decía- piensa que «la religión es cosa de mujeres, y él debe ostentar sus bríos varoniles no creyendo en nada». Ese no creer en nada y el respeto debido al marido hace que ellas no sufran por la falta de religiosidad de sus cónyuges, dado que están convencidas de que ni van a condenarse por no asistir a los oficios religiosos, ni por no confesarse, 
ni por negarse la carne en día de abstinencia, mientras ellas comen pescado (Arenal 1974, 52 y 145).

Doña Emilia, por su lado, denuncia el contraste entre la defensa femenina de la religión y la creciente laicidad masculina:

... la ley, hecha por los hombres, de que, sean ellos lo que gusten -deístas, ateos, escépticos o racionalistas-, sus hijas, hermanas, esposas y madres no pueden ser ni son más que acendradas católicas (34-35).

El inicio de la salida de los ámbitos reservados por el patriarcado a las mujeres, conlleva también una revolución. Este proceso se observa en la presencia cada vez más frecuente, de mujeres y hombres, en locales de baile, en las ciudades y pueblos. Las encuestas fomentadas por el cardenal Francesc Vidal i Barraquer (1922, 1927 y 1932) reflejan la preocupación por este hecho, que se reproduce en toda la demarcación de la Archidiócesis Tarraconense. Aun así, la asistencia y participación de las mujeres a la misa diaria y dominical siempre fue muy superior a la asistencia masculina (Puente prensa).

Miren Llona (283-299) ha señalado la importancia de Concepción Gimeno de Flaquer (1850-1919), escritora y editora, como precursora del tipo de feminismo que más adelante defenderían las mujeres de Acción Católica en los años veinte. Se ha dicho de Gimeno de Flaquer que «adoptó un feminismo conservador en lo ideológico y furioso en la expresión, con bastante arraigo y difusión en la alta burguesía» (Argente 36). Rechaza los argumentos de la ciencia sobre la debilidad -mental y biológica-femenina:

La supuesta inferioridad del sexo femenino no tiene base científica; su debilidad orgánica origínala el encierro en que ha vivido durante tantos siglos, su estrecha limitación a la vida del hogar, la falta de actividad, la carencia de educación física... (Gimeno de Flaquer 1903, 16).

La madre es la transmisora de los valores morales, la esencia de la virtud, quien desarrolla una acción social mediante la beneficencia, o como maestra. Quien ha de influir en la sociedad:

... para ejercer la mujer la triple maternidad física, moral e intelectual, necesita ser ilustrada, este es el requisito indispensable para la conquista del progreso, para la regeneración social, para el engrandecimiento de la patria (Gimeno de Flaquer 1900, 33-35).

Es bien cierto que estas «escritoras de la domesticidad» no formaban todavía parte de ningún movimiento organizado, como también lo es que existen notables coincidencias entre ellas, tantas que podemos afirmar la existencia de una cierta conciencia feminista (Díaz Marcos 30). Sin embargo, ninguna se detuvo en cuestionar el mito mujer-madre y su función reproductora y moralizadora 
de la sociedad (Macoc 163); incluso el anarquismo, cuyas reivindicaciones de género más importantes se realizaron en el orden familiar instituido a principios del siglo XX. En La Voz de la Mujer, periódico anarco-feminista argentino publicado en Buenos Aires de 1896 a 1897, la autora Luisa Violeta apelaba a la función educadora y moralizadora de la mujer obrera anarquista:

Pero no debéis darle una educación o moral burguesa, porque la moral burguesa es una moral corrompida y falsa, y además es la que contribuye a tener sujetos a vuestros hijos a la cadena de la esclavitud [...] No les enseñéis a creer en Dios; enséñales que la religión es la atrofia de la mente, tanto de los hombres como de las mujeres y por tanto es la que impide el desarrollo del progreso; demostradles que la religión es contraria a las leyes naturales, que ella es el símbolo de la ignorancia y de la depravación, y, por fin, que la religión es una farsa que han inventado para que no viéramos más allá de nuestra narices y para que nos entreguemos atados de pies y manos, cual mansos corderos, a nuestros explotadores y tiranos [...] Enseñadles a luchar por la emancipación y por el bienestar humano para llegar de esta manera a ser libres [... $]$ sin preocuparnos de nada ni para nada de la asquerosa educación y de la corrompida moral burguesa...(La Voz de la Mujer, Violeta).

A pesar de las duras críticas hacia la sociedad burguesa, las anarquistas no rompieron con la aparente y consciente responsabilidad como madres:

... ¡Mamá, pan por Dios! Y entonces comprendimos porqué se cae... porqué se mata y porqué se roba (léase expropia).

Y fue entonces también, que desconocimos a ese Dios y comprendimos cuán falsa es su existencia; en suma, que no existe... (La Voz de la Mujer, La Redacción).

\section{EDUCACIÓN}

El liberal Antonio Gil de Zárate, importante ilustrado del XIX, escribe, a mitad siglo, que:

... la cuestión de la enseñanza es cuestión de poder; el que enseña, domina; puesto que enseñar es formar Hombres, y Hombres amoldados a las miras del que los adoctrina. Entregar la enseñanza al clero es querer que se formen hombres para el clero y no para el Estado; es trastornar los fines de la sociedad humana; es trasladar el poder donde debe estar a quien por su misión tiene que ser ajeno a todo poder, a todo dominio; es, en suma, hacer soberano al que no debe serlo [...] la cuestión, ya lo he dicho, es cuestión de poder. Trátese de saber quién ha de dominar a la sociedad: el Gobierno o el clero (Gil de Zárate 146-147).

En una sociedad con altos niveles de analfabetismo, la formación se convirtió en el elemento principal de cambio social. Esta cuestión no pasó sólo por la incorporación de las niñas a la escuela primaria, sino que también se les inculcó 
una moral alejada de dogmas políticos y religiosos que las haría criaturas independientes. La educación, por tanto, era vista como el motor transformador, e intentó contribuir a la realización de la sociedad del futuro, sin división de clases, ni distinción de sexos.

La educación de las niñas, tanto en esta centuria, como en las anteriores, como en las siguientes, es en extremo clasista. Veamos la que reciben las hijas de los pobres, según Pilar Sinués de Marco (1835-1893), escritora, en su popular obra El Ángel del Hogar:

En la clase pobre se crían éstas hasta los ocho años en un completo abandono, como el trigo en los campos de la Mancha. Al cumplirlos, los padres, obligados por la imperiosa ley de la necesidad, sólo estudian la manera de que sus hijas se ganen el necesario alimento, ya que no les sea dado cooperar al sostén de su familia, que siempre suele ser más numerosa de lo conveniente, empero la miseria, que aflige al pueblo, excusa en parte su descuido, por más sensible que nos sea el punible abandono en que viven sus hijas (Sinués 39-41).

En la clase media, en cambio, dice la autora que se dan dos situaciones: o se condena a la mujer a la más absoluta ignorancia - «enseñan a lo sumo a sus hijas a leer, a escribir y las cuatro reglas de la aritmética para que tomen la cuenta a su criada»-o se les concede una educación con hábitos desmesurados e irreales de opulencia, ridículos y perjudiciales:

... en esos colegios no se enseña a las niñas a peinarse solas, ni a mullir su lecho, ni a zurcir su ropa, ni a pegar una cinta en un zapato o un botón en un brodequín; el peinado lo hace una doncella, el lecho lo arregla una criada, y el calzado... el calzado se tira cuando se rompe; así, una hija de un empleado que tiene doce o diez y seis mil reales de sueldo al año, se educa con hábitos de duquesa millonaria, y ipobre del marido que con ella cargue después! (Sinués 39-41).

El punto de encuentro, sin embargo, es la necesidad de educación de la mujer, reivindicada por unas y otras. Así se expresan las peticionarias a las Cortes constituyentes:

Pero si nuestros títulos de madres y esposas no bastaran a legitimar nuestras quejas, la dignidad de mujeres católicas y la influencia que ejerceremos siempre en las costumbres nos dan derecho para hablaros así. [...] los hombres serán siempre lo que nosotras queramos, buenos, virtuosos, grandes, si nosotras les enseñamos a serlo: pero para que esto suceda es menester que nuestra educación sea exclusivamente católica, porque solo el catolicismo enseña las grandes virtudes y solo a él se debe que la mujer ocupe en la tierra el merecido lugar que le corresponda en bien de la moralidad pública, base y fundamento de la verdadera libertad política (Señoras de Valladolid, 28 febrero 1855). 
Como decíamos, la educación es una pieza fundamental del discurso obrero ${ }^{1}$. Bajo el epígrafe de educación integral se encierra la propuesta laica y revolucionaria de las futuras generaciones. La pedagogía es observada como el motor transformador, que contribuiría a la realización de la sociedad del futuro, sin división de clases ni distinción de sexos. Entre 1872 y 1910 tiene lugar un impulso educativo sin precedentes en este país. Los sectores más concienciados quisieron provocar una explosión de conocimiento a través de la cultura librepensadora. Como refiere Ana Muiña, «sus esfuerzos iban dirigidos a conseguir una enseñanza integral que formara, práctica e intelectualmente, a la gente obrera a fin de obtener un desarrollo completo como personas» (106). Esto se aborda desde diferentes aspectos. Por un lado se promueve el ateísmo, los debates y otras formas de sociabilidad; por otro, la lectura. Se intenta generar el espíritu crítico.

Pere Solà, observa la evolución

... de los planteamientos educativos laicistas decimonónicos. ¿Por qué? Pues porque constituyen un antecedente indirecto de la enseñanza racionalista y de la Escuela Moderna. Hasta tal punto resulta esto cierto que, en la mente de muchas personas mayores que conocieron centros de enseñanza llamada racionalista, escuela racionalista es sinónimo de escuela laica. Popularmente, pues, la escuela racionalista de los sindicatos CNT no constituyó más que una modalidad de la antigua escuela laica no confesional (37).

Las federaciones locales anarquistas e internacionalistas empiezan, entonces, a fundar escuelas laicas para pequeños y adultos. Sólo en Cataluña nacen, entre 1882 y 1896, más de 70 centros, génesis de La Escuela Moderna de Francesc Ferrer i Guardia (Muiña 106). Los principales objetivos perseguidos, bajo el lema Ni dogmas ni sistemas, son la enseñanza laica, racionalista, pacifista y gratuita. Esta renovación pedagógica responde a un cambio de las actitudes sociales y políticas, y se representa en dos frentes totalmente opuestos. Por un lado, el movimiento nacional catalán y, por otro, la corriente del laicismo revolucionario (Monés 176). Viene influenciada por la lectura de Rousseau (1712-1778), Pestalozzi (1746-1827), Robin (1837-1912), Faure (1858-1942) o Montessori (1870-1952).

Teresa Mañé cree que la ignorancia es el gran problema, fomentada por la Iglesia y la religión que promueve el analfabetismo y el oscurantismo de los pueblos, pues bajo sus criterios se han ocultado los porqués de la ciencia y de la humanidad. Un dogmatismo -dice- que provoca retraso, no sólo en las

1. Para entender la importancia de las escuelas laicas es necesario trasladarse a un país donde ni siquiera había escuelas públicas garantizadas por el Estado, y donde la educación estaba en la mayoría de ocasiones en manos de la Iglesia, como hemos expuesto. 
investigaciones empíricas, sino también en la sociedad civil (Gustavo 1922). La evolución pedagógica del ideal anarquista se inserta así en un modelo racionalista, de coeducación entre ricos y pobres, aulas mixtas, supresión de la educación religiosa, enseñanza de las relaciones entre poder y trabajo, ausencia de premios y castigos, incorporación del juego entre las actividades didácticas. Una pedagogía siempre sometida a constantes críticas y revisiones (Fuentes 66-67). La revolución social no tendría ningún impacto sin una fase previa de instrucción; sin embargo, Soledad Gustavo se pregunta: « ¿Son buenos todos los métodos de instrucción que recibe el pueblo?» (1891). Para ella la enseñanza pasa por abrazar la idea de libertad y tolerancia, «el amor á la humanidad entera sin distinción de razas ni de religiones: todos somos hermanos en la naturaleza; todos debemos ser educados é instruidos en la escuela de la fraternidad [...]». Se comprueba de esta manera que su propuesta no es adoctrinar, sino brindar mecanismos con los cuales poder llegar a ser personas conscientes.

Las religiones positivas, en sus delirios, han creado siempre odios de raza, han cooperado á la obra de destrucción que durante muchos siglos domina á la humanidad [...] muévenos solamente la idea de hacer un parangón entre la enseñanza oficial y a enseñanza libre ó laica á fin de que de su análisis resulte el bien que esperamos en pro de la institución que defendemos porque lógicamente pensando creemos es la que mejor responde á las conveniencias del presente y del porvenir (1891).

La educación es el medio con el cual conseguir gentes libres y aptas para combatir la ignorancia y el fanatismo. Las escuelas laicas, según Mañé, no son ni ateas ni católicas, sino científicas. Por este motivo no se discrimina. La propuesta docente postula: «Enseñando al niño que la certeza no existe, al ser hombre no encontrará la razón de odiar: faltárale base para fanatizarse en una idea y creerá dogmática. Considerando que poder ser erróneo lo que él piensa, no intentará imponer su creencia a los demás» (Gustavo 1891).

¿Está dentro las leyes de la justicia y de la moral que impongamos una religión en que no se cree, valiéndonos de que una ley ampara esa injusticia?

Por ahí empieza la misión de la enseñanza laica. La ciencia pura sin mistificaciones, el indiferentismo hacia toda clase de religión es el objeto de esa enseñanza. En ella lo mismo cabe el racionalista que el ateo, el materialista que el espiritista; no se acongoja a la conciencia con vanos fantasmas, con absurdos indemostrables, con filosóficas que es incapaz de comprender la inteligencia de un niño... (1891).

Según Soledad Gustavo la enseñanza debe albergar en su seno la idea de la libertad y la tolerancia, el amor a la humanidad sin distinción de razas, ni de 
religiones: «todos somos hermanos en naturaleza, todos debemos ser educados e instruidos en la escuela de la fraternidad».

...Pero si nosotros abogamos en favor de la libertad de enseñanza, no es para que podamos enseñar en las escuelas nuestras ideas ácratas, Como los ortodoxos pretenden que se ensene su religión-, nosotros la queremos, sencillamente, porque queremos la libertad en todo y para todo, y porque tenemos confianza en nosotros, en nuestras ideas y en la misma libertad, que la consideramos superior á cuantas teologías y sistemas filosófico religiosos puedan concebirse... (Gustavo 1904).

Antonia Maymón (1881-1959), pedagoga racionalista, se opone drásticamente a la educación religiosa, pues según la autora ésta fomentaba los egoísmos y las guerras. Debe incorporarse la educación laica en las escuelas, y los maestros han de ser independientes de los poderes civiles y religiosos. Llega a sugerirla renuncia al ejercicio de la enseñanza si no le permiten ejercer su libertad de cátedra.

En ellas se ha de atrofiar el intelecto con una serie de enseñanzas absurdas y ridículas; el profesor, a la cabeza de sus alumnos deberá ser figura decorativa de fiestas religiosas y patrióticas y, en días determinados, el párroco tiene derecho a fiscalizar su enseñanza y comprobar, por sí mismo, si los niños saben más de infierno y gloria que de ecuaciones y cuerpos geométricos. Y en los pueblos, sobre todo, el maestro tiene que cuidar más de la tertulia del cura y del cacique, que de la buena marcha de la escuela. En estas condiciones, ningún profesor que tenga conciencia del racionalismo podrá perder su dignidad profesional y sus convicciones a los pies de una religión, que siempre fue la rémora del progreso, que persiguió a la ciencia y a sus propagadores y que coloca por encima de la verdad y la razón sus dogmas y fanatismos. Yo, y como yo, estoy segura que muchos, de mis compañeros, renuncio a la enseñanza, si para ejercerla tengo que vender mi consciencia, enseñando a los niños cosas que estoy convencida son falsas (Maymón 1925, 3).

Reclama asimismo, y en todo momento, la necesidad de instruir a mujeres y hombres según un mismo modelo.

...Si la enseñanza racionalista reivindicó los derechos de la niña y quiso que se educara junto con el niño, instruyendo su inteligencia a la par de su compañerito de escuela, para hacerlos hermanos y luchadores de un mismo ideal, hoy no basta esto; la eugenesia es algo tan imprescindible para la niña como para cualquier otra asignatura; la naturaleza la ha destinado para la madre, y para tal debe educarse, y si la pedagogía se ha detenido asombrada delante de la anormalidad y ha comprendido que no se corrige con castigos, sino que se cura con una adecuada profilaxis, hemos de reconocer que la eugenesia es indispensable para las futuras madres, que no han de producir carne de cañón y de explotación para perpetuar la esclavitud humana (Maymón 1932, 3).

Feminismo/s 28, diciembre 2016, pp. 25-47 
En 1932, Maymón tuvo que dejar la escuela. La prensa local la persigue. En su favor, La Verdad publica el testimonio de una de las alumnas, quien reconoce: «Se tuvo que ir porque la criticaban, porque no enseñaba religión. Ya ves, yo, si quería, luego iba a la iglesia [...] a mí me gustaba mucho esa escuela, pero mi madre al final me sacó de allí» (1932, mayo). También Maymón contesta las acusaciones por su defensa de la escuela racionalista:

... Las que delante de María Inmaculada, toda lirios y azahares, rezan sus diarias oraciones; las que delante del Nazareno, todo llagas y pasión, olvidan que su sangre se derramó por justos y pecadores, no temen mancillar la pureza de la niñez con insinuaciones que yo, por falsas, desprecio; aunque, según sus creencias, tendrán que rendir cuenta de ellas a quien perdonó a María de Magdalena, porque amó mucho y condenó a Epulón por negar a Lázaro las migajas de su mesa. Creo inútil prestarme a discutir, donde y cuando quieran, sus doctrinas y las mías, porque sé que no han de aceptarlo (Maymón 1932).

De todas formas, nadie se plantea seriamente la insuficiencia de la educación tradicional femenina hasta después de la Revolución de 68, cuando el esfuerzo de los krausistas organizando conferencias-Conferencias dominicales para la mujer-y creando escuelas, consiguen que la opinión pública se interese por el tema. Según el rector de la Universidad de Madrid, en la memoria del curso 1868-69,

Los profesores han dedicado sus principales esfuerzos $[\ldots]$ a deshacer preocupaciones arraigadas y fatales, a fijar los puntos más importantes sobre qué deben versar la educación y la instrucción de la mujer, esclareciendo el concepto de éstas en los diversos órdenes y fines de la vida, desde el doméstico al religioso ${ }^{2}$.

Aunque ve clara la misión de la mujer, afirmando que su destino en la vida es ser madre: madre de un hogar doméstico y madre de la sociedad. A pesar de ello, uno de los principales objetivos de las conferencias es el político; esos hombres están movidos por la intención de contrarrestar los efectos de la ignorancia, y para persuadir a sus mujeres a fin de que no obedezcan ciegamente los dictados reaccionarios de la religión oficial. Por lo tanto despiertan la hostilidad de la Iglesia, ejemplarizada en las palabras del sacerdote Julio Alarcón (1843-1924), arremetiendo contra

...el exclaustrado y excomulgado F. de Castro [el rector] y sus malvados compañeros, que apoyan la causa de las mujeres sólo para seguir adelante con sus propios planes siniestros y cuyo concepto de la emancipación de la mujer es sinónimo de la emancipación del deber, de la dignidad, de la honestidad y más que todo de la religión (Alarcón 471).

2. Boletín-Revista de la Universidad de Madrid 244, 1869-1870.

Feminismo/s 28, diciembre 2016, pp. 25-47 
Según Pardo Bazán la liberación de la mujer sólo puede alcanzarse a través de una sólida y completa educación, como expone con vehemencia en el Congreso pedagógico celebrado en Madrid en 1892. Allí se discute si la mujer tiene derecho a recibir la preparación capaz de habilitarla para el desempeño de cualquier profesión. El resultado ilustra significativamente la situación: 260 votos a favor, 293 en contra, 89 abstenciones (Campo Alange 161). Eco encuentra en Concepción Arenal -La educación de la mujer ${ }^{3}$ - mientras doña Emilia defiende el suyo: La educación del hombre y de la mujer, sus relaciones y diferencias, en el que reivindica con ardor los derechos de las mujeres en cuanto a educación y acceso al mundo laboral en cualquier ámbito. No olvidemos que las primeras universitarias españolas se matriculan en 1872, 1874 y 1877, y que la más precoz -Elena Maseras- nunca podrá ejercer la carrera que estudia en primera opción (Cuadrada 2016). Sólo a partir de 1910, cuando Pardo Bazán es nombrada Consejero de Instrucción Pública, se permite a las mujeres inscribirse libremente en la Universidad.

Arenal aboga por la supresión de las diferencias entre la educación de la mujer y del hombre. Reconoce que la formación ha de ser mayor para el género femenino, dado que la necesita más, a causa de las desventajas naturales y sociales que sufre. Especialmente para paliar la frivolidad, esclavitud o prostitución: «a la mujer no se la respeta porque no es respetable, y no es respetable porque no se la respeta». Insiste en la obligación del trabajo como fin y contribución a la felicidad, consuelo en la desgracia e incluso deber para las de las clases acomodadas sin necesidad de ganarse la vida. Defiende con énfasis la participación activa en las cuestiones sociales, en la beneficencia: prisiones, hospitales, manicomios, hospicios, inclusas: «se trata de practicar las obras de misericordia, ni más, ni menos». Considera igualmente apta a la mujer para la enseñanza:

La mujer es paciente, afectuosa, insinuante; no le falta perspicacia; si convenientemente se la educa e instruye, comprenderá y aun adivinará, si el discípulo atiende, se distrae o se cansa, hasta dónde entiende ésa y encontrará medios de que aprenda lo que es capaz de aprender.

Respalda asimismo la aptitud de la mujer para las demás profesiones, añadiendo que los conocimientos «especiales y superiores» puede aprenderlos en su casa, constatando que con la enseñanza privada, «sin más intervención oficial que los exámenes», hay bastante. Y por ello mismo y

respecto a los que exigen la asistencia a los establecimientos públicos, esperamos que los hombres se irán civilizando lo bastante para tener orden y

3. Las citas siguientes se basan en esta fuente.

Feminismo/s 28, diciembre 2016, pp. 25-47 
compostura en las clases a que asistan mujeres, como la tienen en los templos, en los teatros, en todas las reuniones honestas, donde hay personas de los dos sexos.

Gimeno de Flaquer, en La mujer española. Estudios acerca de su educación y sus cualidades intelectuales (1877) sostiene que el hombre contempla el acceso de la mujer a la cultura como una amenaza capaz de poner en peligro su protagonismo en la vida pública y su posición privilegiada en la familia (Ayala):

El hombre ha querido ciega a su compañera, para que no le viese caminar por sendas cubiertas de fango vil; la ha querido sin criterio para que no le pidiera cuenta de su conducta ligera y para subyugarla sin razonamiento de ninguna especie ante las despóticas leyes de su caprichosa fantasía; ha comprendido el hombre que, al suavizarse las costumbres, el cetro del mundo pertenece a los reyes de la inteligencia, y para doblegar a su compañera, sometiéndola a un ominoso yugo y a una postración moral muy lamentable, ha mutilado sus facultades intelectuales y la ha sepultado en las tinieblas, sumiéndola en la más oscura ignorancia...

A lo largo de los 16 capítulos que conforman su obra, doña Concepción ataca al hombre como principal causante de la discriminación femenina y, con pareja fogosidad, clama por la imperiosa necesidad de abrir las puertas del mundo de la cultura e inteligencia a las mujeres. Las artes -pintura, música, literatura-y los conocimientos científicos -astronomía, física, química, medicina, higieneson caminos idóneos para alcanzar la deseada igualdad entre ambos sexos y para el desarrollo eficaz de la educación de sus propios hijos.

\section{SUMA Y SIGUE}

A inicios del s.Xx, el feminismo conservador y católico, vinculado con el feminismo nacionalista, temeroso de la influencia que los movimientos feministas europeos lleguen a tener en España, opta por constituir rápidamente organizaciones femeninas afines a sus doctrinas. Inicialmente, la Iglesia y la derecha española atacan virulentamente al feminismo, a raíz de la inclusión formal de los derechos de las mujeres en los programas de las organizaciones de izquierda. Además, desaprueban los argumentos utilizados por las propias mujeres, sustentados en la igualdad, por su posible cuestionamiento de los principios de la doctrina católica. Dicha doctrina se afianza sobre la institución familiar, en la cual la mujer desempeña su papel natural de sumisión al hombre.

La idea de crear un feminismo católico, siguiendo el modelo del sindicalismo de igual cuño, obedece a la necesidad de contrarrestar la influencia del liberalismo. Se debe destacar la influencia que ejerce entonces la Iglesia en la sociedad española y, en especial, en la educación femenina. Paradójicamente, 
entre las demandas que este feminismo moderado está dispuesto a aceptar, se incluye el sufragio femenino. La creencia de que el voto femenino es un voto esencialmente conservador y confesional les empuja a desarrollar una política posibilista a favor del sufragio de las mujeres; sin embargo, se oponen a la participación activa de ellas en la política, ya que consideran que el ámbito público es de los hombres, y una participación articulada y prolongada de las mujeres en la política puede generar desavenencias dentro de la familia.

Entre las organizaciones femeninas inspiradas por el catolicismo conservador destaca La Junta de Damas de la Unión Ibero-Americana de Madrid, formada por mujeres católicas de clase alta, cuya actividad se centra en aspectos básicamente asistenciales. No abogan por la obtención de derechos políticos sino por mejorar las condiciones de trabajo y fomentar la educación femenina. En el año 1919, se funda Acción Católica de la Mujer en España, que funciona como una asociación caritativa vinculada a las clases acomodadas. El objetivo de dicha organización es neutralizar las organizaciones de mujeres, abogando por un feminismo católico, crítico con las demás organizaciones, incluidas las conservadoras y nacionalistas a las que acusaban de mantener una actitud demasiado neutral ante la religión. Dentro de dicha organización se articularon progresivamente diferentes corrientes: la más conservadora dirigida por Consuelo González Ramos alrededor de la revista La Voz de la Mujer (19171931) -con la paradoja del mismo título que la revista argentina de fines del XIX, pero tan antagónica ideológicamente-; la progresista -encabezada por María Espinosa de los Monteros (1875-1924) - y la centrista representada por la Marquesa de Ter (1864-1936).

En un primer instante, en las últimas décadas del siglo XIX, el anarquismo se muestra reacio a incorporar el término feminismo en sus propuestas. Se considera que éste es un término de las mujeres sufragistas y, por tanto, de aquellas que quieren continuar reproduciendo un modelo de sociedad desigual, clasista e injusto; contrariamente, el anarquismo, en su intención de destruir los órganos de poder, reivindicó que la sociedad futura no sería posible sin incorporar a las mujeres al proceso de formación y estructuración. A pesar de todo, poco a poco, sobre todo a partir de la aparición de Mujeres Libres, las anarquistas empiezan a aceptar y a utilizar la palabra feminismo. Las propuestas, a pesar de las diferencias entre ellas, confluyen en la idea del indispensable laicismo. La religión es la causa de la exclusión, desigualdad y el retraso. Por ello, se aparta de las escuelas, de las celebraciones y los festejos. Las escuelas ácratas constituyen la creación de una alternativa vigorosa, entusiasta y esperanzada: el nido del germen que hará crecer la sociedad nueva. 
$* * *$

Unas y otras, a pesar de sus tremendas diferencias, incluso enfrentadas en posiciones antagónicas, compartieron la visión de un mundo que había de cambiar. De la necesidad de un cambio en el que las mujeres habían de tener un protagonismo especialísimo. Ya fuera desde la práctica conservadora de la filantropía y la beneficencia abocada a la atención de pobres, presos o enfermos -con lo que entonces comportó de acceso a espacios públicos tradicionalmente vetados (Cuadrada 2017)-; ya fuera desde la queja y el descontento por la hipocresía social y la doble moral; ya fuera por el cuestionamiento de las prácticas religiosas, el matrimonio, el papel de la mujer en la vida familiar y en la formación de la prole; ya fuera desde la reivindicación constante e insistente de la necesaria educación y capacitación de las niñas; ya fuera por la reclamación de los derechos de las mujeres empezando por el del voto y el acceso a la ciudadanía...

Ya fuera. Y sí, fue, pero por tan poco tiempo, y con un final tan atroz que sólo de imaginar el dolor, el desaliento y la terrible tristeza de tantas luchas, esperanzas y deseos truncados, rotos, bañados en sangre, se nos pone la carne de gallina y nos estremecemos.

Para todas nuestro reconocimiento. No las olvidamos.

\section{REFERENCIAS BIBLIOGRÁFICAS}

\section{Fuentes}

Alarcón y Meléndez, Julio. «El feminismo sin Dios», Razón y Fe, año 1, agosto 1901. Archivo Histórico Archidiocesano de Tarragona (AHAT), Encuestas de Vidal i Barraquer, 1922, 1927, 1932.

Constitución, http://www.congreso.es/est_sesiones/Legislatura 1854-1856. Constituyentes, consultado el 08-07-2016.

Gil de Zárate, Antonio. De la Instrucción pública en España. Madrid: Imprenta del Colegio de Sordo-Mudos, 1855.

Gimeno de Flaquer, Concepción, El problema feminista. Madrid: Huérfanos de S.C. de Jesús, 1903.

Gimeno de Flaquer, Concepción, Evangelios de la mujer. Madrid: Librería de Fernando de Fe, 1900.

Guerra, Pepita. «¿Amemos? No ¡Luchemos». La Voz de la Mujer, 31 enero 1896

Gustavo, Soledad. «Divulgación Científica: La edad de la tierra». La Velocidad, 1 febrero 1922.

Gustavo, Soledad. «De la Enseñanza Anza». La Revista Blanca, 15 febrero 1904.

Gustavo, Soledad. «La enseñanza laica». Las Circunstancias, 5 abril 1891. 
Gustavo, Soledad. «Mi primer triunfo». El Vendaval, 28 enero 1888.

Lavera, Carmen. «El AMOR LIBRE». La Voz de la Mujer, 8 enero 1896.

Maymón, Antonia. «Racionalismo». Solidaridad Humana, 1 junio 1932.

Maymón, Antonia. «En legítima defensa y por una SOLA vez». La Verdad, 11 junio 1932.

Maymón, Antonia. «El miedo a la libertad». La Verdad, 10 marzo 1932.

Maymón, Antonia. «A mis alumnos». La Verdad, 17 septiembre 1932.

Maymón, Antonia. «Acción Social Obrera. Órgano de los sindicatos de la provincia de Gerona adheridos a la CNT de Sant Feliu de Guíxols» 397 (1925): 3.

Pardo Bazán, Emilia. La mujer española y otros artículos feministas. Selección y prólogo de Leda Schiavo. Madrid: Editora Nacional, 1976.

Proudhon, Pierre-Joseph. La Pornocracia o la cuestión de las mujeres en los tiempos modernos, 1875.

Sinués de Marco, M. ${ }^{a}$ del Pilar. El ángel del hogar. Estudios morales acerca de la mujer. Ed. María del Pilar Sinués. Madrid: Impr. Española de Nieto y Comp, 1862.

Violeta, Luisa. «¡Madres, educad bien a vuestros hijos!». La Voz de la Mujer, 15 mayo 1896.

\section{Bibliografía}

Ackelsberg, Martha. Mujeres Libres. Barcelona: Virus Editorial, 2000.

Agulló, M. ${ }^{a}$ Carmen y M. ${ }^{a}$ Pilar Molina. Antonia Maymón, anarquista, maestra, naturalista, Barcelona: Virus, 2014.

Alari, Marta y Ginés Puente. «De Soledad Gustavo a Teresa Mañé: un breure corregut per la premsa anarquista de finals del segle XIX». La Corbella 2 (2015): $11-44$.

Álvarez Junco, José. La ideología política del anarquismo español (1868-1910). Madrid: Siglo XXI, 1976.

Andrés Argente, Josefina. Escritoras y periodistas en Madrid (1876-1926). Madrid: Área de Gobierno de Empleo y Servicios a la Ciudadanía, Dirección General de Igualdad de Oportunidades, Ayuntamiento de Madrid, 2007.

Arenal, Concepción. La educación de la mujer, http://www.cervantesvirtual.com/ obra-visor-din/la-educacion-de-la-mujer-0/html/fef9f6e6-82bl-1ldf-acc7002185ce6064_2.html\#I_1_, consultado el 09-07-2016.

Arenal, Concepción. La emancipación de la mujer en España. Madrid: Biblioteca Júcar, 1974.

Ayala Aracil, M. ${ }^{a}$ de los Ángeles. La mujer española. Estudios acerca de su educación y sus cualidades intelectuales, http://www.cervantesvirtual.com/portales/ concepcion_arenal/obra-visor-din/la-mujer-espaola-de-concepcin-gimeno-deflaquer-0/html/018b8ba4-82b2-11df-acc7-002185ce6064_5.html, consultado el 09-07-2016. 
Bieder, Maryellen. «Women, Literature, and Society. The Essays of Pardo Bazán». Spanish Women Writters and the Essay. Gender, Politics and the Self. Eds. Kathleen M. Glenn y Mercedes Mazquiarán de Rodríguez. Columbia \&Londres: University of Missouri Press, 1998, 25-54.

Biglia, Barbara. «Corporeizando la epistemología feminista: investigación activista feminista». Subjetivación femenina: investigación, estrategias y dispositivos críticos. Comp. Martha Liévano Franco y Marina Duque Mora. Nuevo León: Universidad Autónoma de Nuevo León, 2012, 195-229.

Bonnassiolle Cortés y Marcelo Alejandro. «En contra de Dios, la religión y la Iglesia. Ateísmo, Antiteísmo y Anticlericalismo en el discurso anarquista chileno (1899-1913)». Historia Caribe 25 (2014): 71-116.

Campo Alange y Condesa de María Laffitte. La mujer en España: Cien años de su historia (1860-1960). Madrid: Aguilar: 1964.

Cuadrada, Coral. «El ejemplo del Plannig de Tarragona (ayer) vs. Facebook (hoy)». I Coloquio Internacional Haciendo Historia: Género y Transición Política. Transiciones en Marcha. Alicante: Centro de Estudios sobre la Mujer, Universidad de Alicante, 2015, 112-126.

Cuadrada, Coral. «Pioneres Mèdiques». Emprius (Centre d'Estudis Vilasecans) 1 (2017) [en prensa].

Cueva Merino, Julio de la. «Si los curas y frailes supieran... la violencia anticlerical». Violencia política en la España del siglo XX. Dir. Santos Julià. Madrid: Taurus, 2000, 191-233.

Díaz Marcos, Ana María. Salirse del Tiesto: Ensayistas españolas, feminismo y emancipación (1861-1923), Oviedo: KRK, 2012.

England, Kim V.L. «Getting personal: Reflexivity, positionality and feminist research». The Professional Geographer 46 (1994): 80-89.

Espigado Tocino, Gloria. Las mujeres en el anarquismo español 1869-1939. Madrid: La Neurosis o Las Barricadas ed., 2015.

Ferré Trill, Xavier (ed.). ¡Guerra a Dios! Tarragona: Publicacions URV, 2013.

Fuentes Codera, Maximiliano. «Teresa Mañé i Miravent (1865-1939): el pensament educatiu anarquista i l'escola laica». Vint Mestres i pedagógues catalanes del segle XX. Coord. Joan Soler Mata, Barcelona: Associació de Mestres Rosa Sensat, 2015, 66-67.

Llona, Miren. «El feminismo católico en los años veinte y sus antecedentes ideológicos» Vasconia 25 (1998): 283-299.

Macoc, Lucía. «Feminismo e Identidades políticas a principios del siglo XX en la Argentina. Construcciones discursivas sobre la Mujer en el socialismo y el anarquismo». CUADERNOS del Ciesal jóvenes investigadores 9 (2011): 152-173.

Marín i Silvestre, Dolors y Salvador Palomar Abadia. Els MontsenyMañé: un laboratori de les idees. Reus: Carrutxa, 2010. 
Monés, Jordi. El pensament escolar i la renovació pedagògica a Catalunya (18331938). Barcelona: La Magrana, 1995.

Muiña, Ana. Rebeldes periféricas del siglo XIX. Madrid : La linterna sorda, 2008.

Prado, Antonio. Matrimonio, familia y estado: Escritoras anarco-feministas en La Revista Blanca (1898-1936). Madrid: Fundación de Estudios Libertarios Anselmo Lorenzo, 2011.

Puente, Ginés. «El control de la moralitat a la a la parròquia de Sant Pere de Tarragona». Església i Franquisme. A.D. Tarragona: Publicacions URV, [En prensa].

Puente, Ginés. De Soledad Gustavo a Teresa Mañé (1865-1939). Trabajo de final de máster: Estudios de Mujeres, Género y Ciudadanía, Universidad de Barcelona, septiembre 2016.

Scanlon, Geraldine M. La polémica feminista en la España Contemporánea (18681974). Madrid: Akal, 1986.

Solà, Pere. «La escuela y la educación en los medios anarquistas de Cataluña, 1909-1939». CONVIVIUM 44-45 (1975): 37-54.

Soler Mata, Joan. «Introducción: Els processos de renovació pedagògica a Catalunya al llarg del segle XX». Vint Mestres i pedagógues catalanes del segle XX. Coord. Joan Soler Mata, Barcelona: Associació de Mestres Rosa Sensat, 2015, 11-55.

Vilafranca Manguán, Isabel. «La filosofía de la educación de Rousseau: el naturalismo eudamonista». Educació i Història: Revista d'Història de l'Educació19 (2012): 35-53. 
